\title{
Spontaneous Neutrophil Activation in HTLV-1 Infected Patients
}

Jaqueline B. Guerreiro ${ }^{1}$, Maria Aurélia F. Porto ${ }^{1}$, Silvane B. Santos ${ }^{1}$, Lino Lacerda ${ }^{1}$, John L. Ho ${ }^{2}$ and Edgar M. Carvalho'

\author{
Immunological Service of the Universitary Hospital Prof. Edgard \\ Santos, Federal University of Bahia ${ }^{I}$; Salvador,BA, Brazil; Weill \\ Medical College of Cornell University², New York, NY, USA.
}

\begin{abstract}
Human T cell lymphotropic Virus type-1 (HTLV-1) induces lymphocyte activation and proliferation, but little is known about the innate immune response due to HTLV-1 infection. We evaluated the percentage of neutrophils that metabolize Nitroblue tetrazolium (NBT) to formazan in HTLV-1 infected subjects and the association between neutrophil activation and IFN- $\gamma$ and TNF$\alpha$ levels. Blood was collected from 35 HTLV-1 carriers, from 8 patients with HAM/TSP (HTLV-1associated myelopathy); 22 healthy individuals were evaluated for spontaneous and lipopolysaccharide (LPS)-stimulated neutrophil activity (reduction of NBT to formazan). The production of IFN- $\gamma$ and TNF- $\alpha$ by unstimulated mononuclear cells was determined by ELISA. Spontaneous NBT levels, as well as spontaneous IFN- $\gamma$ and TNF- $\alpha$ production, were significantly higher $(p<0.001)$ in HTLV-1 infected subjects than in healthy individuals. A trend towards a positive correlation was noted, with increasing percentage of NBT positive neutrophils and levels of IFN- $\gamma$. The high IFN- $\gamma$ producing HTLV-1 patient group had significantly greater NBT than healthy controls, $43 \pm 24 \%$ and $17 \pm 4.8 \%$ respectively $(p<0.001)$, while no significant difference was observed between healthy controls and the low IFN- $\gamma$-producing HTLV-1 patient group $(30 \pm 20 \%)$. Spontaneous neutrophil activation is another marker of immune perturbation resulting from HTLV-1 infection. In vivo activation of neutrophils observed in HTLV-1 infected subjects is likely to be the same process that causes spontaneous IFN- $\gamma$ production, or it may partially result from direct IFN- $\gamma$ stimulation.

Key Words: HTLV-1, IFN- $\gamma$, TNF- $\alpha$, LPS, neutrophil activation.
\end{abstract}

Human T cell leukemia virus type-I(HTLV-1) infects an estimated ten million people worldwide, making it a serious public health problem [1]. The majority of HTLV1 infected individuals are asymptomatic; however, a small percentage of HTLV-1 infected people develop severe diseases, such as HTLV-1 associated myelopathy, tropical spastic paraparesis (HAM/TSP), and adult Tcell leukemia/lymphoma (ATLL) [2]. The immune response in HTLV-1 infection is characterized by lymphocyte activation and proliferation and spontaneous

Received on 15 May 2005; revised 27 September 2005. Address for correspondence: Dr. E.M. Carvalho - Serviço de Imunologia, Hospital Universitário Prof. Edgard Santos, UFBA, Rua João das Botas s/n, Canela, Zip code: 40110-160, BA, Brazil. Phone (55.71) 3237-7353, Fax: (55.71) 3245-7110, email:imuno@ufba.br.

The Brazilian Journal of Infectious Diseases 2005;9(6):510-514 (C) 2005 by The Brazilian Journal of Infectious Diseases and Contexto Publishing. All rights reserved. production of IFN- $\gamma$, IL- 2 and TNF- $\alpha[3,4]$. This predominant type- 1 immune response is observed in both HTLV-1 carriers and in patients with HAM/TSP, although the exaggerated $\mathrm{T}$ cell activation is predominant in patients with HAM/TSP [5,6]. Little is known about innate immunity in this retroviral infection. The spontaneous production of cytokines in vivo may activate neutrophils, which are cells involved in defense against bacteria, viruses and fungi [7]. However, there is no information about neutrophil function in HTLV-1 infected subjects. While it is known that patients with HTLV-1 may develop disseminated helminthic infection, caused by Strongyloides stercoralis, and severe Norwegian scabies [8,9], HTLV-1 infected subjects do not have an increased risk of systemic bacterial and fungal diseases.

Neutrophil NADPH oxidase is critical for defense against invading microbes [7]; activation by microbial 
products, such as lipopolysaccharide (LPS) or host cytokines (TNF- $\alpha$, IFN- $\gamma$ ) leads to assembly of multicomponent NADPH oxidase and a resultant oxidative burst [10], which is readily detected by the reduction of nitroblue tetrazolium (NBT) to formazan, within cells that generated the respiratory burst [11]. Decreased NBT levels are characteristic of chronic granulomatous disease (CGD), a syndrome in which one or more components of NADPH oxidase are absent or defective [7]; it has also been observed in patients with AIDS [12]. We evaluated neutrophil function in patients with HTLV-1 using the NBT test. Considering that neutrophil function can be enhanced by the cytokine environment, IFN- $\gamma$ and TNF- $\alpha$ levels were also measured in supernatants of mononuclear cell cultures.

\section{Material and Methods}

\section{$\underline{\text { Patients }}$}

Forty-three patients from the HTLV-1 Clinic of the Hospital Universitário Prof. Edgard Santos, Federal University of Bahia participated in our study. These patients were chosen among 102 cases that were admitted to the clinic from September 2002 to August 2004, based on the following criteria: diagnosis of HTLV-1 confirmed by Western blot, willingness to participate in the study, and negative serologies for HIV, syphilis, hepatitis B and hepatitis C. Furthermore, individuals with acute bacterial or viral infection, patients with diabetes and those using immunomodulator drugs, such as corticosteroids and beta-interferon, were excluded. Thirty-five of these individuals were detected by two blood banks in Salvador and had asymptomatic HTLV-1 infection, being considered HTLV-1 carriers, and eight cases had a diagnosis of HAM/TSP, based on the Osame disability criteria [13]. Twenty-two volunteers composed of healthy employees and graduate students, who had negative serology for HTLV-1, participated as the control group. This study was approved by the Ethical Committee of the Hospital Universitário Professor Edgard Santos, and informed consent was obtained from the participants.

\section{$\underline{\text { NBT test }}$}

The NBT test was performed as previously described by PARK [14] and modified by Bellinati-Pires [15] to check for the influence of technical factors, such as temperature, heparin concentration and time [16] Briefly, heparinized venous blood ( $1 \mathrm{~mL}$ ) was incubated for 15 minutes at room temperature with cell culture medium or cell culture medium containing $75 \mu \mathrm{g} / \mathrm{mL}$ lipopolysaccharide (LPS from $E$ coli, Sigma Chemical Co., St. Louis, MO). After incubation with NBT $(2 \mu \mathrm{g} /$ $\mathrm{mL}$ ) (Sigma Chemical Co.) for $15 \mathrm{~min}$. at $37^{\circ} \mathrm{C}$, the number of cells containing formazan was visualized using a Neubauer chamber and recorded with a camera. The results were expressed in percentage of cells that reduced the NBT to formazan (herein called NBT positive).

\section{Mononuclear Cell culture and measurement of IFN- $\gamma$} and TNF- $\alpha$

Peripheral blood mononuclear cells (PBMC) were isolated from heparinized venous blood by ficoll-hypaque. After washing with saline, the cell concentration was adjusted to 3x10\%/mL in RPMI 1640 (Gibco, Grand Island, NY, USA) plus 10\% heat inactivated human AB $\mathrm{Rh}+$ serum (Sigma Chemical Co., St. Louis, MO), antibiotics and glutamine. Aliquots of $3 \times 10^{6} \mathrm{cells} / \mathrm{mL}$ were incubated at $37^{\circ} \mathrm{C}$ in $5 \% \mathrm{CO} 2$ atmosphere. The cells were incubated without stimulus for 72 hours and supernatants were collected. IFN- $\gamma$ and TNF- $\alpha$ levels were measured by sandwich ELISA technique (R\&D System, Minneapolis, MN) and the results expressed in $\mathrm{pg} / \mathrm{mL}$.

\section{Results}

Spontaneous activation of neutrophil NADPH oxidase, measured as NBT positive cells, though it was highly variable in HTLV-1 infected subjects (range 10\% to $85 \%$ ), it was significantly greater than in healthy subjects (mean \pm standard deviation), $39 \pm 23 \%$ and $17 \pm 4.8 \%$, respectively ( $<<0.001$, Figure 1$)$. When the spontaneous NBT test results of 35 HTLV-1 carriers were compared with that from $8 \mathrm{HAM} / \mathrm{TSP}$, the 
percentage of spontaneous NBT positive neutrophils in patients with HAM/TSP was greater than HTLV-1 carriers, but the difference was not significant, $45.4 \pm 17.4$ and $37 \pm 21 \%$, respectively (mean $\pm \mathrm{SD}, \mathrm{P}>0.05$ ). The significantly lower percentage of NBT positive neutrophils at baseline in healthy controls could be functionally enhanced by LPS stimulation ( $73 \pm 14 \%$ cells), which argues against a spurious result of this assay. In addition, the percentage of spontaneous NBT positive neutrophils in a subset of HTLV-1 carriers $(n=22)$ following stimulation with LPS was further augmented, from $32 \pm 21.6 \%$ to $78 \pm 11.6$ and confirmed the accuracy of the NBT assay. Moreover, white cell counts performed by automated cytometer complemented with a manual differential showed that neutrophil counts in HTLV-1 carriers were different (but not significantly) from those observed in healthy subjects, $4955 \pm 2018$ cells $/ \mathrm{mm}^{3}$ and $6737 \pm 1836$ cells/ $\mathrm{m}^{3}$, respectively (mean $\pm \mathrm{SD}, \mathrm{p}=0.06$ ).

The percentage of NBT positive neutrophils in HTLV-1 patients were next correlated with the level of spontaneous IFN- $\gamma$ production in the HTLV-I infected subjects $(n=22)$ and healthy controls $(n=22)$. Consistent with previous reports, spontaneous IFN- $\gamma$ production in HTLV-1 infected subjects $(1551 \pm 1952)$ was higher $(\mathrm{p}<0.001)$ than that observed in healthy controls $(8 \pm 13 \mathrm{pg} / \mathrm{mL})$. A correlation analysis between percentage of NBT-positive cells with IFN- $\gamma$ levels indicated a positive but non-significant tendency. The highly variable levels of IFN- $\gamma$ in HTLV-1 infected subjects (range: 0 to $7835 \mathrm{pg} / \mathrm{mL}$ ) led us to separate these patients into two subgroups, termed as high and low IFN- $\gamma$ groups (range: 821 to $7835 \mathrm{pg} / \mathrm{mL}$ and 0 to $567 \mathrm{pg} / \mathrm{mL}$, respectively). The mean levels of IFN- $\gamma$ in the high and low IFN- $\gamma$ groups were significantly different, $2824 \pm 2090 \mathrm{pg} / \mathrm{mL}$ versus $277 \pm 212 \mathrm{pg} / \mathrm{mL}$, respectively $(\mathrm{p}<0.05)$ (Figure 2$)$. The mean percentage of NBT-positive cells in the high IFN- $\gamma$ group was greater (but not significantly) than that observed in the low IFN$\gamma$ group, $43 \pm 6 \%$ and $30 \pm 5.1 \%$ respectively. However, the percentage of NBT-positive cells was significantly greater in the high IFN- $\gamma$ patient group than in healthy subjects ( $p<0.001)$; however, the NBT test results did not differ significantly between the low IFN- $\gamma$ HTLV-1 patient group and the healthy controls (Figure 3). TNF$\alpha$ levels in HTLV-1 infected individuals were significantly greater than in healthy controls $(251 \pm 386.5 \mathrm{pg} / \mathrm{mL}$ and $31 \pm 27 \mathrm{pg} / \mathrm{mL}$, respectively, $\mathrm{p}<0.001)$. However there was no significant correlation between TNF- $\alpha$ levels and the percentage of NBT-positive neutrophils in HTLV-1 patients (data not shown).

\section{Discussion}

The NBT test is a simple method to evaluate neutrophil NADPH oxidase function; the percentage of cells that metabolizeNBT to formazan without an activation stimulus is usually low [16]. Upon stimulation with LPS, there is a significant increase in the number of formazan-containing cells, indicating cell activation. We found that the percentage of spontaneous positive NBT cells is higher in HTLV-1 infected subjects than in HTLV-1 seronegative controls; this increase was not due to differences in the number of neutrophils; it may be due to the high IFN- $\gamma$ production observed in HTLV-1 infected subjects.

The ability of HTLV-1 to infect various cell types, such as lymphocytes, macrophages, dendritic cells and endothelial cells, in vitro, has been documented [17, 18]. Neutrophils can also be infected by the virus, but the predominant cell type infected by HTLV-1 is the T cells [19]. It has been shown that the HTLV-1 tax gene is able to transactivate some other cellular genes, such as IL-2, IL-2r, GM-CSF and IL-15, leading to T-cell activation and spontaneous proliferation $[4,20,21]$. Spontaneous production of high levels of IFN- $\gamma$, and to a lesser extent of TNF- $\alpha$, is characteristic of HTLV-1 infection [6]; these cytokines activate phagocytes to induce them to kill bacteria [22,23]. However, other mechanisms in addition to IFN- $\gamma$ production participated to activate neutrophils, because even though HAM/TSP patients produce significantly more IFN- $\gamma$ than HTLV1 carriers [6], the percentage of NBT-positive neutrophils was not increased in HAM/TSP in comparison with asymptomatic carriers. Therefore, it is possible that HTLV-1 can directly activate neutrophils or that other cytokines in addition to IFN- $\gamma$ may participate in neutrophil activation during this viral infection. 
Figure 1. Percentage of cells expressing formazan (NBT test) in HTLV-I carriers, patients with HAM/ TSP and healthy subjects. Both HTLV-I carriers and patients with HAM/TSP had a greater spontaneous reduction of NBT than did controls.

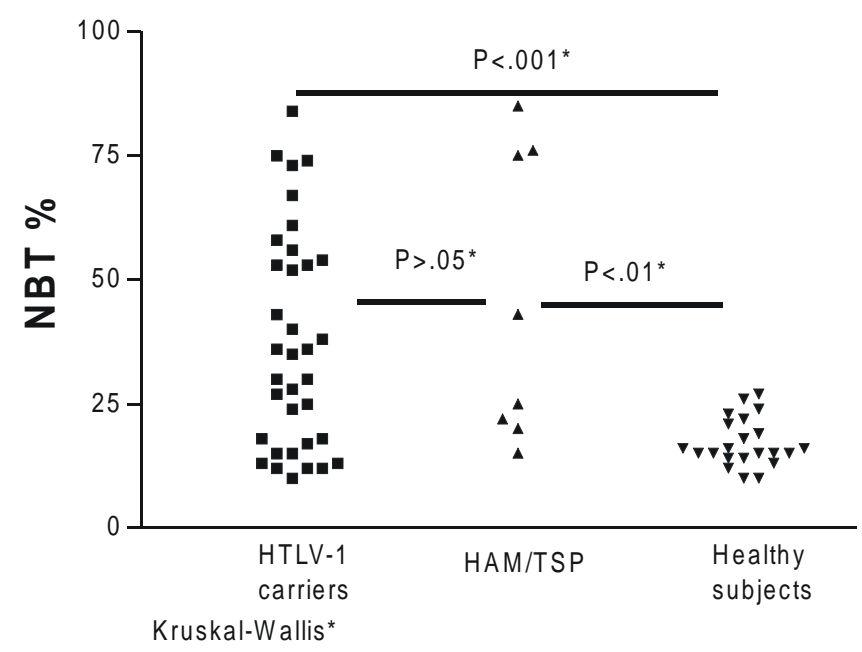

Figure 2. Levels of IFN- $\gamma$ production in HTLV-1 infected patients classified as high IFN- $\gamma$ producers and low IFN- $\gamma$ producers and in healthy subjects. The production of high and low IFN- $\gamma$ patients was at higher levels than in the controls.

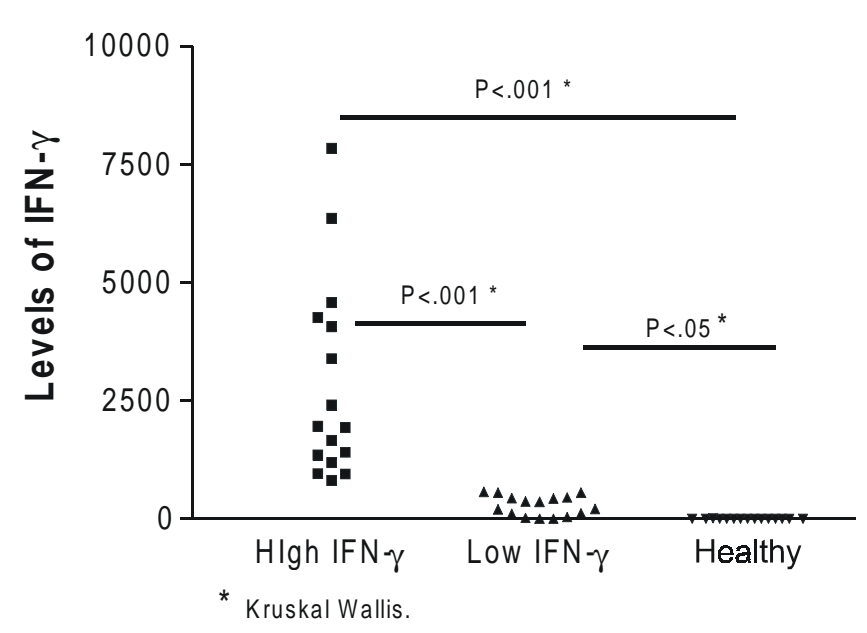

Figure 3. Percentage of cells expressing formazan (NBT test) in HTLV-I high IFN- $\gamma$ producers, in patients with low IFN- $\gamma$ production and healthy subjects. High IFN- $\gamma$ producers patients had a greater spontaneous reduction of NBT than did the controls.

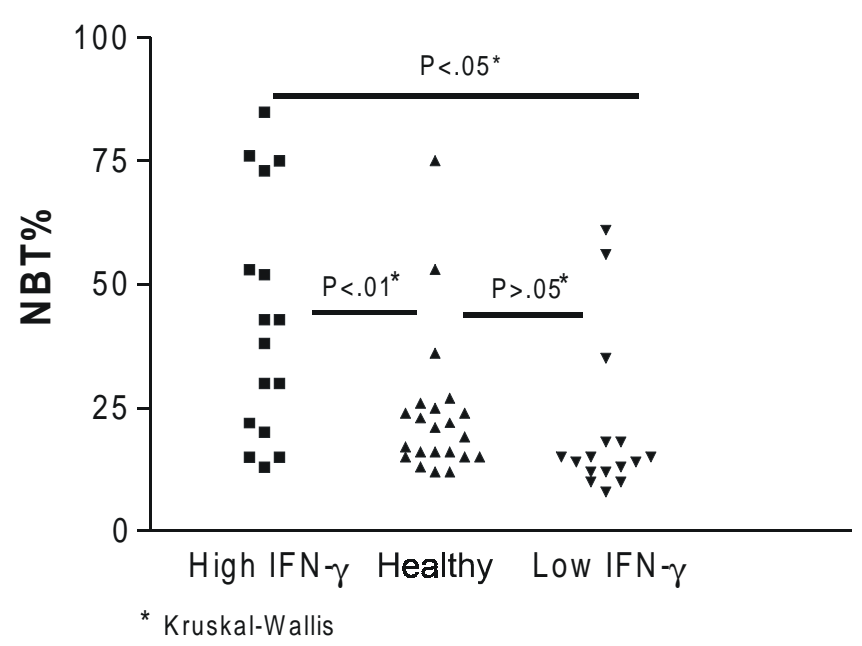

Previous studies have shown that simultaneous infection with S. stercoralis and HTLV-1 is associated with recurrent and disseminated strongyloidiasis [9], and there are also reports of association of severe Norwegian scabies with HTLV-1 infection [8]. As in HTLV-1, there is a decrease in IL-4, IL-5 and IgE synthesis; one can understand the increased susceptibility to helminth and mite infections, since the defense mechanisms against these agents are mediated by a type- 2 immune response. There is no evidence that HTLV-1 increases susceptibility to or changes the clinical course of bacterial infections. It is possible that the increase in NBT observed in HTLV-1 infection prevents the development of severe infection by extra-cellular bacteria, which are the main agents killed by neutrophils.

Spontaneous neutrophil activation determined by the simple and inexpensive NBT method is an additional marker for immune disorders resulting from HTLV-1 infection. Though the trend for a direct correlation between IFN- $\gamma$ levels and the percentage of formazanpositive cells may indicate that IFN- $\gamma$ secretion is partially related to neutrophil activation in this disease; it is possible that this viral infection and the tax protein of HTLV-1 participate in neutrophil activation. 


\section{Acknowledgements}

We thank DrMaria Ilma Araújofor technical assistance andElbeSilvafor preparation of the manuscript. This study was financially supported by the Brazilian National Research Council $(\mathrm{CNPq})$ Fundação de Amparo à Pesquisa do Estado da Bahia (FAPESB) and NIH Grant TW007127. Dr. Edgar M. Carvalho is a senior investigator of CNPq.

\section{References}

1. Edlich R.F., Arnette J.A., Williams F.M. Global epidemic of human T-cell lymphotropic virus type-I (HTLV-I). J Emerg Med 2000;18:109-19.

2. McFarlin D.E., Blattner W.A. Non-AIDS retroviral infections in humans. Annu Rev Med 1991;42:97-105.

3. Biddison W.E., Kubota R., Kawanishi T., et al. Human T cell leukemia virus type I (HTLV-I)-specific CD8+ CTL clones from patients with HTLV-I-associated neurologic disease secrete proinflammatory cytokines, chemokines, and matrix metalloproteinase. J Immunol 1997; 159:2018-25.

4. Uchiyama T., Hori T., Tsudo M., et al. Interleukin-2 receptor (Tac antigen) expressed on adult T cell leukemia cells. J Clin Invest 1985; 76:446-53.

5. Itoyama Y., Minato S., Kira J., et al. Spontaneous proliferation of peripheral blood lymphocytes increased in patients with HTLV-I-associated myelopathy. Neurology 1988;38:1302-7.

6. Santos S.B., Porto A.F., Muniz A.L., et al. Exacerbated inflammatory cellular immune response characteristics of HAM/TSP is observed in a large proportion of HTLVI asymptomatic carriers. BMC Infect Dis 2004;4:7.

7. Dinauer M.C., Lekstrom-Himes J.A., Dale D.C. Inherited neutrophil disorders: Molecular basis and new therapies. Hematology (Am Soc Hematol Edu program) 2000:303-18.

8. Gotuzzo E., Arango C., de Queiroz-Campos A., Isturiz R.E. Human T-cell lymphotropic virus-I in Latin America. Infect Dis Clin North Am 2000;14:211-39.

9. Sato Y., Shiroma Y., Kiyuna S., et al. Reduced efficacy of chemotherapy might accumulate concurrent HTLV-1 infection among strongyloidiasis patients in Okinawa, Japan. Trans R Soc Trop Med Hyg 1994;88:59.

10. Cassatella M.A., Bazzoni F., Flynn R.M., et al. Molecular basis of interferon-gamma and lipopolysaccharide enhancement of phagocyte respiratory burst capability. Studies on the gene expression of several NADPH oxidase components. J Biol Chem 1990;265:20241-6.
11. Baehner R.L., Boxer L.A., Davis J. The biochemical basis of nitroblue tetrazolium reduction in normal human and chronic granulomatous disease polymorphonuclear leukocytes. Blood 1976;48:309-13.

12. Sonnerborg A., Jarstrand C. Nitroblue tetrazolium (NBT) reduction by neutrophilic granulocytes in patients with HTLV-III infection. Scand J Infect Dis 1986; 18:101-3.

13. Osame M., Usuku K., Izumo S., et al. HTLV-I associated myelopathy, a new clinical entity. Lancet 1986;1:1031-2.

14. Park B.H., Holmes B.M., Rodey G.E. and Good R.A. Nitroblue-tetrazolium test in children with fatal granulomatous disease and newborn infants. Lancet 1969; $1: 157$.

15. Bellinati-Pires R., Carneiro-Sampaio M.M., Colletto G.M. Functional evaluation of human neutrophils. Is the bactericidal activity correlated with nitroblue tetrazolium reduction? J Investig Allergol Clin Immunol 1992;2:14653.

16. Bjorksten B. The influence of technical factors on the NBT test. Scand J Haematol 1974;12:46-50.

17. Valentin H., Lemasson I., Hamaia S., et al. Transcriptional activation of the vascular cell adhesion molecule-1 gene in T lymphocytes expressing human T-cell leukemia virus type 1 Tax protein. J Virol 1997;71:8522-30.

18. Knight S.C., Macatonia S.E., Cruickshank K., et al. Dendritic cells in HIV-1 and HTLV-1 infection. Adv Exp Med Biol 1993;329:545-9.

19. Richardson J.H., Edwards A.J., Cruickshank J.K., et al. In vivo cellular tropism of human T-cell leukemia virus type 1. J Virol 1990;64:5682-7.

20. Miyatake S., Seiki M., Yoshida M., Arai K. T-cell activation signals and human T-cell leukemia virus type I-encoded p40x protein activate the mouse granulocytemacrophage colony-stimulating factor gene through a common DNA element. Mol Cell Biol 1988;8:5581-7.

21. Jacobson S., Krichavsky M., Flerlage N., Levin M. Immunopathogenesis of HTLV-I associated neurologic disease: massive latent HTLV-I infection in bone marrow of HAM/TSP patients. Leukemia 1997;11 Suppl 3:73-5.

22. Murray H.W., Gellene R.A., Libby D.M., et al. Activation of tissue macrophages from AIDS patients: in vitro response of AIDS alveolar macrophages to lymphokines and interferon-gamma. J Immunol 1985; 135:2374-7.

23. Cassatella M.A., Cappelli R., Della Bianca V., et al. Interferon-gamma activates human neutrophil oxygen metabolism and exocytosis. Immunology 1988;63:499506. 